\title{
Widening socio-economic disparities in early childhood obesity in Los Angeles County after the Great Recession
}

\author{
Tabashir Z Nobari ${ }^{1,2, *}$, Shannon E Whaley ${ }^{2}$, Catherine M Crespi ${ }^{3}$, Michael L Prelip ${ }^{1}$ and \\ May C Wang \\ 'Department of Community Health Sciences, UCLA Fielding School of Public Health, 650 Charles E. Young Drive \\ South, Los Angeles, CA 90095, USA: ${ }^{2}$ Public Health Foundation Enterprises WIC Program, Irwindale, CA, USA: \\ ${ }^{3}$ Department of Biostatistics, UCLA Fielding School of Public Health, Los Angeles, CA, USA
}

Submitted 26 September 2017: Final revision received 26 January 2018: Accepted 22 February 2018: First published online 2 April 2018

\begin{abstract}
Objective: While economic crises can increase socio-economic disparities in health, little is known about the impact of the 2008-09 Great Recession on obesity prevalence among children, especially low-income children. The present study examined whether socio-economic disparities in obesity among children of preschool age participating in a federal nutrition assistance programme have changed since the recession.

Design: A pre-post observational study using administrative data of pre-schoolaged programme participants from 2003 to 2014. Logistic regression was used to examine whether the relationship between obesity prevalence (BMI $\geq 95$ th percentile of the Centers for Disease Control and Prevention's growth charts) and three measures of socio-economic status (household income, household educational attainment, neighbourhood-level median household income) changed after the recession by examining the interaction between each socioeconomic status measure and a 5-year time-period variable (2003-07 v. 2010-14), stratified by child's age and adjusted for child's sociodemographic characteristics. Setting: Los Angeles County, California, USA.

Subjects: Children aged 2-4 years ( $n$ 1637788) participating in the Special Supplemental Nutrition Program for Women, Infants, and Children.

Results: The magnitude of the association of household income and household education with obesity increased after 2008-09 among 3- and 4-year-olds and 2- and 3year-olds, respectively. However, the magnitude of the association of neighbourhoodlevel median household income with obesity did not change after 2008-09.

Conclusions: Disparities in obesity by household-level socio-economic status widened after the recession, while disparities by neighbourhood-level socio-economic status remained the same. The widening household-level socio-economic disparities suggest that obesity prevention efforts should target the most vulnerable low-income children.
\end{abstract}

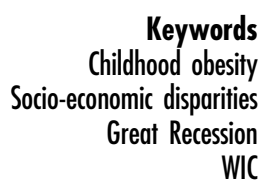

Unlike prior recessions, the Great Recession ('the recession') resulted in many American households experiencing multiple hardships from unemployment, reduced income, foreclosures and loss of health insurance ${ }^{(1,2)}$. Low socio-economic status (SES) and ethnic minority households were disproportionately affected, experiencing higher rates of unemployment and underemployment, and higher losses in income ${ }^{(3,4)}$. The impact of an economic crisis such as the recession on health and wellbeing, especially among low-income households, can exacerbate socio-economic disparities in health ${ }^{(5)}$. In the present study, we attempt to investigate the potential impact of the recession (December 2007-June 2009) on socio-economic disparities in early childhood obesity in low-income communities in Los Angeles County (LAC), California, USA, a region that is home to some of the largest inequalities in the $\mathrm{USA}^{(6)}$.

In the USA, economic downturns are, in general, associated with improved physical health ${ }^{(7,8)}$, partly due to improvements in health behaviours such as smoking, obesity and physical activity during these downturns ${ }^{(9,10)}$. Indeed, studies occurring before the recession found increased unemployment, an indicator for economic conditions, to be associated with decreased risk of obesity ${ }^{(8,9)}$. However, minority and low-SES men were found to be at increased risk of obesity during an economic 
downturn ${ }^{(11)}$. A few studies have examined the impact of the recession on obesity among adults in the USA. The results are mixed with some studies finding an increase in obesity risk ${ }^{(12)}$, other studies finding a decrease (among White adults) $^{(13)}$ and yet others finding no effect ${ }^{(2)}$. Even less is known about the impact of the recession on childhood obesity in the USA; one study among California school-aged children found that increased county-level unemployment during the recession was associated with increased risk of overweight ${ }^{(14)}$.

It could be argued that an economic crisis could influence childhood obesity risk in either direction. The three main mechanisms posited by which recessions might affect health are changes in time use, consumption and stress ${ }^{(15)}$. Unemployment or underemployment could mean that parents have more leisure time to participate in time-intensive health behaviours like cooking home-cooked meals and engaging in physical recreational activities with children ${ }^{(8-10,15-17)}$. However, the reduced income from working fewer hours might mean eating more inexpensive, energy-dense foods like fast foods, leading to excessive weight gain, especially among low-SES families ${ }^{(15,18)}$. Greater leisure time might also mean more time for sedentary behaviours like watching television $^{(16)}$

The fear of becoming unemployed and the financial strain resulting from unemployment or underemployment can increase parents' stress ${ }^{(15)}$. Economic downturns are associated with an increase in poor mental health and suicides ${ }^{(7,8,11,19)}$. Exposure to chronic stressors like financial strain or to mothers' stress and depression, both in utero and during the early years of childhood, can increase obesity risk among young children by deregulating their stress response system, influencing the pathways that regulate body composition and metabolic function, and by creating an obesogenic home environment for the child ${ }^{(20)}$.

We hypothesize that the recession's effect on childhood obesity risk may be greater among the most vulnerable households who live in communities with few resources $^{(3,4)}$ to support the successful implementation of nutrition education programmes. To test this hypothesis, we examine pre-school-aged participants in the Special Supplemental Nutrition Program for Women, Infants, and Children (WIC). WIC provides nutritional support and education, breast-feeding support, and referrals to medical and social services to low-income $(\leq 185 \%$ of the federal poverty level (FPL)) and nutritionally at-risk pregnant, breast-feeding and postpartum women, and infants and children less than 5 years old. In the USA, $40 \%$ of families with children of pre-school age are eligible to participate in WIC ${ }^{(21)}$ and in LAC half of all young children participate in $\mathrm{WIC}^{(22)}$.

We use a unique data set established in 2003 by the Public Health Foundation Enterprises WIC Program (PHFE-WIC), the largest local WIC agency in the country, that merges neighbourhood-level data with household-level data for children participating in WIC in LAC. This data set allows us to examine changes in the prevalence of early childhood obesity over time while considering the influences of the communities in which they live, providing insights into trends of early childhood obesity prevalence among low-income households. For example, despite reports of decreasing rates of early childhood obesity prevalence for the nation ${ }^{(23)}$ and also for $\mathrm{LAC}^{(24)}$, an analysis of the PHFE-WIC data set revealed that obesity prevalence has continued to climb for 2-5-year-olds in some of the poorest neighbourhoods in $\mathrm{LAC}^{(25)}$, suggesting perhaps that intervention efforts made to address childhood obesity have not reached or adequately addressed the needs of the most vulnerable communities.

Leveraging LAC's unique characteristics, our primary objective is to determine whether socio-economic disparities in obesity prevalence among children of preschool age widened in the years following the 2008-09 recession compared with the years prior to the recession. Understanding this is key to developing and implementing effective obesity prevention efforts that address the specific needs of this socially and economically vulnerable population.

\section{Methods}

Administrative data from WIC pre-school-aged participants from 2003 to 2014 for LAC were used for the present study. The data belong to the State of California WIC Program and are maintained by the WIC Data Mining Project, a research partnership which is funded by First 5 LA (http:// www.first5la.org/). Sociodemographic and anthropometric information on all participants since 2003 is included in the database. Height and weight measurements for children are obtained every six months by trained WIC clinic staff who follow a standardized protocol; as a result, measurements have high validity ${ }^{(26)}$. One unique aspect of this WIC data set is that WIC participants' addresses are geocoded into census tracts. As a result, we were able to link census tract-level socio-economic data from the US Census Bureau's American Community Survey (ACS) to the WIC participants. Because ACS tract-level data provide only 5-year estimates, the 2003-09 WIC administrative data were linked to 2005-09 estimates; and the 2010-14 administrative data were linked to 2010-14 estimates.

For the current pre-post observational study, we excluded the years when the recession occurred (2008 and 2009) to allow for a comparison of disparities before and after the recession. The analyses were stratified by child's age (2, 3 and 4 years) since, due to rapid growth, young children are developmentally and nutritionally different at every age ${ }^{(27)}$.

Observations were included if they represented a child's first weight/height measurement in a calendar year and if the measurement occurred in the years 2003-07 or 2010-14. Children with complete information were included in the 
final sample ( $n$ 1637788, with 597506 2-year-olds, 577069 3-year-olds and 463213 4-year-olds). To avoid issues of dependency, if twins or triplets participated in WIC, only one of the children was included in our sample. Since children can participate in WIC up until their fifth birthday, the same child could be included in multiple samples. Fifty-three per cent of children were in one subsample, 33\% were in two and $15 \%$ were in three. The UCLA Institutional Review Board approved the protocol for the present study.

\section{Variables}

BMI $\left(=[\right.$ weight $\left.(\mathrm{kg})] /[\text { height }(\mathrm{m})]^{2}\right)$ was calculated from child's measured weight and height. Obesity status was determined by the child having a BMI $\geq 95$ th percentile of the Centers for Disease Control and Prevention's genderand age-specific growth reference values ${ }^{(28)}$.

Three indicators of a child's SES were examined, two at the household level and one at the neighbourhood level. (i) Household income, the total income of the child's household from all sources, is determined by WIC. It was operationalized as a percentage of the FPL $(\leq 50.0 \% \mathrm{FPL}$; 50.1-100.0 \% FPL; 100·1-133.0\% FPL; 133.1-185.0 \% FPL). (ii) Household education, a more stable measure of SES, is the highest grade completed by the child's parent (less than high school; high school; some college; college or more). (iii) Median household income is an indicator of neighbourhood resources and is a 5-year estimate of median household income of residents in the child's census tract it was categorized according to quartiles of its distribution among WIC participants $(\leq \$ 32738$; \$32 739-40 278; \$40 279-51 534; $\geq \$ 51535$ ). As a reference, the highest neighbourhood income group has a lower median income than that of all of LAC ( $\$ 55746$ in 2014 US dollars $)^{(29)}$. For these three socio-economic measures, dummy variables were used in the analyses with the highest SES group as the reference.

A binary 5-year time-period variable (2003-07 v. 2010-14) based on the calendar year the child was weighed and measured was used to indicate period of measurement relative to the recession. Analyses were stratified by child's age and adjusted for child's gender and parent's race/ ethnicity. Dummy variables of parent's race/ethnicity (Hispanic, non-Hispanic White, non-Hispanic Black and Asian) were created with Hispanic as the reference group, since the majority of the sample had Hispanic parents.

\section{Statistical analysis}

The $\chi^{2}$ test was used to determine whether participants' sociodemographic characteristics were different during the two time periods. To determine the best way to model the secular trends, calendar year was entered into the regression models as a binary time-period variable (2003-07 v. 2010-14), as dummy variables for each year in comparison to the reference, 2003 (e.g. $2004 v$. 2003), and as linear, quadratic and cubic terms. Based on the Akaike information criterion and predicted probability charts, the binary year variable which excluded the recession years provided one of the best fits for the data since it allowed for the flexibility to model the increasing trends up until 2008 and the decreasing trends beginning in 2010. Logistic regression analysis was then applied to examine the association of childhood obesity with each socio-economic measure, stratified by child's age and adjusted for time period, child's gender and parent's race/ethnicity. To determine if the impact of the socio-economic measure on childhood obesity increased after the recession, an interaction term (socio-economic measure $\times$ time period) was included in the regression model. The equation for child $i$ is:

$$
\begin{aligned}
\operatorname{Logit}[P(Y=1)]= & \beta_{0}+\beta_{1}\left(\text { SES }_{i}\right)+\beta_{2}\left(\text { Gender }_{i}\right) \\
& +\beta_{3}\left(\text { Race } / \text { ethnicity }_{i}\right)+\beta_{4}\left(\text { Time period }_{i}\right) \\
& +\beta_{5}\left(\text { SES }_{i} \times \text { Time period }_{i}\right)+e_{i},
\end{aligned}
$$

where $Y$ is the $\log$ odds that child $i$ is obese, $\beta_{0}$ is the intercept across the sample of children, $\beta_{1}, \ldots, \beta_{5}$ are the effects of the predictors (regression coefficients) on obesity, and $e_{i}$ is random error.

To determine if disparities changed in the years following the recession compared with the years prior to the recession, the statistical significance of the interaction term was examined using the omnibus Wald $\chi^{2}$ test statistic which tests for overall statistical difference. Tests for statistical significance were based on $P<0.05$. Analyses were conducted using the statistical software package SAS version 9.4.

\section{Results}

Between 2003-07 and 2010-14, obesity prevalence increased for all three age groups (Table 1, and online supplementary material, Supplemental Table 1, for the $95 \% \mathrm{CI}$ ). At the same time, the sociodemographic makeup of the WIC population in LAC also changed. The percentage of children from the poorest households (household income $\leq 50 \% \mathrm{FPL}$ ) increased by over $35 \%$ (Table 1 ). Interestingly, the percentage of children with parents who had at least a high-school education increased by over $20 \%$ during this time (Table 1).

A statistically significant negative relationship between childhood obesity and each of the SES measures was observed (Table 2, and online supplementary material, Supplemental Table 2, for the $95 \%$ CI). The magnitude of the gradient varied according to SES measure, age and time period, and was greatest by household education (Table 2).

\section{Multivariate analyses}

\section{Household income}

Among 2-year-old children, living in lower-income households was associated with significantly higher odds of 
Table 1 Sociodemographic characteristics (\%) of children of pre-school age participating in the Special Supplemental Nutrition Program for Women, Infants, and Children in Los Angeles County, California, USA, by age and time period, 2003 to 2014

\begin{tabular}{|c|c|c|c|c|c|c|}
\hline & \multicolumn{2}{|c|}{$\begin{array}{l}\text { 2-year-olds } \\
\text { (n 597506) }\end{array}$} & \multicolumn{2}{|c|}{$\begin{array}{l}\text { 3-year-olds } \\
\text { (n } 577069 \text { ) }\end{array}$} & \multicolumn{2}{|c|}{$\begin{array}{l}\text { 4-year-olds } \\
\text { (n 463213) }\end{array}$} \\
\hline & $\begin{array}{c}2003-07 \\
(n 319754)\end{array}$ & $\begin{array}{c}2010-14 \\
(n 277752)\end{array}$ & $\begin{array}{c}2003-07 \\
(n 305320)\end{array}$ & $\begin{array}{c}2010-14 \\
(n 271749)\end{array}$ & $\begin{array}{c}2003-07 \\
(n 244132)\end{array}$ & $\begin{array}{c}2010-14 \\
(n 219081)\end{array}$ \\
\hline Child's gender (female) & $49 \cdot 0$ & $49 \cdot 0$ & $48 \cdot 9$ & $48 \cdot 9$ & 48.9 & $48 \cdot 9$ \\
\hline Child is obese & $15 \cdot 8$ & $16 \cdot 6^{\star \star \star}$ & $18 \cdot 4$ & $19 \cdot 2^{\star \star \star}$ & $20 \cdot 1$ & $20 \cdot 6^{\star \star \star}$ \\
\hline \multicolumn{7}{|l|}{ Parent race/ethnicity } \\
\hline Non-Hispanic White & $4 \cdot 3$ & $3 \cdot 3^{\star \star \star}$ & $4 \cdot 2$ & $3 \cdot 1^{\star \star \star}$ & $4 \cdot 2$ & $3 \cdot 0^{\star * *}$ \\
\hline Non-Hispanic Black & $7 \cdot 2$ & $7 \cdot 6$ & $7 \cdot 1$ & $7 \cdot 1$ & 6.9 & $6 \cdot 4$ \\
\hline Asian & $4 \cdot 3$ & $3 \cdot 8$ & $4 \cdot 2$ & $3 \cdot 6$ & $4 \cdot 0$ & 3.5 \\
\hline Hispanic & $84 \cdot 1$ & $85 \cdot 3$ & 84.6 & $86 \cdot 3$ & 84.8 & $87 \cdot 2$ \\
\hline \multicolumn{7}{|l|}{ Household income } \\
\hline$\leq 50.0 \% \mathrm{FPL}$ & $22 \cdot 6$ & $31 \cdot 9^{\star \star \star}$ & $22 \cdot 6$ & $30 \cdot 8^{\star \star \star}$ & $22 \cdot 6$ & $30 \cdot 1^{\star \star *}$ \\
\hline $50 \cdot 1-100 \cdot 0 \% \mathrm{FPL}$ & $45 \cdot 7$ & $44 \cdot 7$ & $45 \cdot 8$ & 45.9 & $46 \cdot 1$ & $47 \cdot 2$ \\
\hline $100 \cdot 1-133.0 \% \mathrm{FPL}$ & $17 \cdot 9$ & $13 \cdot 7$ & $17 \cdot 8$ & $13 \cdot 6$ & $17 \cdot 8$ & $13 \cdot 5$ \\
\hline $133 \cdot 1-185 \cdot 0 \% \mathrm{FPL}$ & $13 \cdot 8$ & $9 \cdot 8$ & $13 \cdot 8$ & $9 \cdot 7$ & $13 \cdot 5$ & $9 \cdot 4$ \\
\hline \multicolumn{7}{|l|}{ Household education } \\
\hline Less than high school & $59 \cdot 2$ & $49 \cdot 0^{\star \star \star}$ & $60 \cdot 5$ & $50 \cdot 6^{\star \star \star}$ & $61 \cdot 6$ & $52 \cdot 5^{\star \star \star}$ \\
\hline High school & $30 \cdot 0$ & $36 \cdot 2$ & $29 \cdot 2$ & 35.5 & $28 \cdot 6$ & $34 \cdot 3$ \\
\hline Some college & $8 \cdot 3$ & $10 \cdot 7$ & $7 \cdot 9$ & $10 \cdot 2$ & $7 \cdot 7$ & $9 \cdot 6$ \\
\hline College or more & 2.5 & $4 \cdot 0$ & $2 \cdot 3$ & 3.7 & $2 \cdot 2$ & 3.6 \\
\hline \multicolumn{7}{|l|}{ Median household income } \\
\hline$\leq \$ 32738$ & $24 \cdot 8$ & $25 \cdot 7^{\star \star \star}$ & 24.9 & $25 \cdot 8^{\star \star \star}$ & 24.9 & $25 \cdot 9^{\star \star \star}$ \\
\hline$\$ 32739-40278$ & $26 \cdot 1$ & $23 \cdot 2$ & $26 \cdot 2$ & 23.5 & $26 \cdot 2$ & 23.7 \\
\hline$\$ 40279-51534$ & $25 \cdot 3$ & 24.4 & $25 \cdot 3$ & 24.5 & $25 \cdot 5$ & $24 \cdot 6$ \\
\hline$\geq \$ 51535$ & 23.9 & $26 \cdot 8$ & $23 \cdot 6$ & $26 \cdot 2$ & $23 \cdot 4$ & $25 \cdot 8$ \\
\hline
\end{tabular}

FPL, federal poverty level.

${ }^{\star} P<0.05,{ }^{\star \star} P<0.01,{ }^{\star \star \star} P<0.001\left(x^{2}\right.$ test measuring differences by time period).

†Obesity defined as $\mathrm{BMI} \geq 95$ th percentile of the Centers for Disease Control and Prevention's gender- and age-specific growth reference values ${ }^{(28)}$. łlncome measured in 2014 US dollars.

Table 2 Prevalence of obesity† (\%) among children of pre-school age participating in the Special Supplemental Nutrition Program for Women, Infants, and Children in Los Angeles County, California, USA, by age and socio-economic indicators, 2003 to 2014

\begin{tabular}{|c|c|c|c|c|c|c|}
\hline & \multicolumn{2}{|c|}{$\begin{array}{l}\text { 2-year-olds } \\
\text { (n 597 506) }\end{array}$} & \multicolumn{2}{|c|}{$\begin{array}{l}\text { 3-year-olds } \\
\text { (n } 577 \text { 069) }\end{array}$} & \multicolumn{2}{|c|}{$\begin{array}{l}\text { 4-year-olds } \\
\text { (n 463213) }\end{array}$} \\
\hline & $\begin{array}{c}2003-07 \\
(n 319754)\end{array}$ & $\begin{array}{c}2010-14 \\
(n 277752)\end{array}$ & $\begin{array}{c}2003-07 \\
(n 305320)\end{array}$ & $\begin{array}{c}2010-14 \\
(n 271749)\end{array}$ & $\begin{array}{c}2003-07 \\
(n 244132)\end{array}$ & $\begin{array}{c}2010-14 \\
\text { (n 219081) }\end{array}$ \\
\hline \multicolumn{7}{|l|}{ Household income } \\
\hline$\leq 50.0 \% \mathrm{FPL}$ & $16 \cdot 6^{\star \star \star}$ & $17 \cdot 5^{\star \star \star}$ & $18 \cdot 6^{\star \star \star}$ & $19 \cdot 6^{\star \star \star}$ & $20 \cdot 2^{\star \star}$ & $20 \cdot 7^{\star \star *}$ \\
\hline $50 \cdot 1-100 \cdot 0 \% \mathrm{FPL}$ & $15 \cdot 8$ & $16 \cdot 6$ & $18 \cdot 5$ & 19.5 & $20 \cdot 3$ & $21 \cdot 2$ \\
\hline $100 \cdot 1-133 \cdot 0 \% \mathrm{FPL}$ & 15.5 & $15 \cdot 9$ & $18 \cdot 2$ & $18 \cdot 4$ & $20 \cdot 2$ & 19.5 \\
\hline $133 \cdot 1-185 \cdot 0 \% \mathrm{FPL}$ & $14 \cdot 8$ & $15 \cdot 0$ & $17 \cdot 6$ & $17 \cdot 3$ & $19 \cdot 4$ & $18 \cdot 9$ \\
\hline \multicolumn{7}{|l|}{ Household education } \\
\hline Less than high school & $16 \cdot 5^{\star \star \star}$ & $17 \cdot 7^{\star \star \star}$ & $19 \cdot 2^{\star \star \star}$ & $20 \cdot 3^{\star \star \star}$ & $21 \cdot 0^{\star \star \star}$ & $21 \cdot 7^{\star \star \star}$ \\
\hline High school & $15 \cdot 2$ & $16 \cdot 3$ & $17 \cdot 4$ & $18 \cdot 7$ & $19 \cdot 1$ & $19 \cdot 9$ \\
\hline Some college & $13 \cdot 7$ & $14 \cdot 6$ & $16 \cdot 6$ & $17 \cdot 1$ & $17 \cdot 7$ & $18 \cdot 8$ \\
\hline College or more & $11 \cdot 1$ & 11.4 & $13 \cdot 9$ & $14 \cdot 4$ & $16 \cdot 2$ & $15 \cdot 8$ \\
\hline \multicolumn{7}{|l|}{ Median household income } \\
\hline$\leq \$ 32738$ & $16 \cdot 9^{\star \star \star}$ & $17 \cdot 6^{\star \star \star}$ & $19 \cdot 5^{\star \star \star}$ & $20 \cdot 4^{\star \star \star}$ & $21 \cdot 1^{\star \star \star}$ & $21 \cdot 7^{\star \star \star}$ \\
\hline$\$ 32739-40278$ & $16 \cdot 2$ & $17 \cdot 2$ & $19 \cdot 0$ & $19 \cdot 8$ & $20 \cdot 9$ & $21 \cdot 3$ \\
\hline$\$ 40279-51534$ & $15 \cdot 3$ & $16 \cdot 5$ & $17 \cdot 9$ & $19 \cdot 1$ & $19 \cdot 9$ & $20 \cdot 4$ \\
\hline$\geq \$ 51535$ & $14 \cdot 6$ & $15 \cdot 2$ & $16 \cdot 9$ & $17 \cdot 6$ & $18 \cdot 5$ & $19 \cdot 0$ \\
\hline
\end{tabular}

FPL, federal poverty level.

${ }^{\star} P<0.05,{ }^{* \star} P<0.01,{ }^{\star \star *} P<0.001\left(x^{2}\right.$ test measuring differences by time period).

†Obesity defined as $\mathrm{BMI} \geq 95$ th percentile of the Centers for Disease Control and Prevention's gender- and age-specific growth reference values ${ }^{(28)}$. flncome measured in 2014 US dollars.

obesity after adjusting for child's gender, parent's race/ethnicity and time period (Table 3, Model 1). Notably, those living in the poorest households ( $\leq 50 \% \mathrm{FPL})$ experienced the highest odds of being obese (OR $=1 \cdot 18$; $95 \%$ CI 1.15 ,
$1 \cdot 21)$. The odds of obesity were greater in 2010-14 than in 2003-07. To determine if the association between household income and childhood obesity was different between the two time periods, an interaction term between household 
Table 3 Multiple logistic regression results: effects of household income on obesity in children of pre-school age participating in the Special Supplemental Nutrition Program for Women, Infants, and Children in Los Angeles County, California, USA, 2003 to $2014 \dagger$

\begin{tabular}{|c|c|c|c|c|c|c|c|c|c|c|c|c|}
\hline & \multicolumn{4}{|c|}{$\begin{array}{l}\text { 2-year-old children } \\
(n 597506)\end{array}$} & \multicolumn{4}{|c|}{$\begin{array}{c}\text { 3-year-old children } \\
(n 577069)\end{array}$} & \multicolumn{4}{|c|}{$\begin{array}{c}\text { 4-year-old children } \\
(n 463213)\end{array}$} \\
\hline & \multicolumn{2}{|c|}{ Model 1} & \multicolumn{2}{|c|}{ Model 2} & \multicolumn{2}{|c|}{ Model 1} & \multicolumn{2}{|c|}{ Model 2} & \multicolumn{2}{|c|}{ Model 1} & \multicolumn{2}{|c|}{ Model 2} \\
\hline & OR & $95 \% \mathrm{Cl}$ & OR & $95 \% \mathrm{Cl}$ & OR & $95 \% \mathrm{Cl}$ & OR & $95 \% \mathrm{Cl}$ & OR & $95 \% \mathrm{Cl}$ & OR & $95 \% \mathrm{Cl}$ \\
\hline \multicolumn{13}{|l|}{ Income } \\
\hline$\leq 50.0 \% \mathrm{FPL}$ & $1 \cdot 18$ & $1.15,1.21$ & & & 1.13 & $1 \cdot 10,1 \cdot 16$ & & & 1.09 & $1.06,1.12$ & & \\
\hline $50 \cdot 1-100 \cdot 0 \% \mathrm{FPL}$ & 1.06 & $1.04,1.09$ & & & 1.08 & $1.05,1.10$ & & & 1.06 & $1.04,1.09$ & & \\
\hline $\begin{array}{l}\text { 100.1-133.0\% FPL } \\
\text { (133.1-185.0\% FPL, Ref.) }\end{array}$ & 1.04 & $1.01,1.07$ & & & 1.04 & $1.01,1.06$ & & & 1.02 & $0.99,1.05$ & & \\
\hline $\begin{array}{l}2010-14 \text { time period } \\
\text { (2003-07, Ref.) }\end{array}$ & 1.05 & $1.03,1.06$ & & & 1.04 & $1.03,1.05$ & & & 1.01 & $1.00,1.03$ & & \\
\hline \multicolumn{13}{|l|}{$\begin{array}{l}\text { Income } \times \text { time period } \\
\leq 50.0 \% \mathrm{FPL}\end{array}$} \\
\hline In 2003-07 & & & 1.18 & $1.14,1.22$ & & & 1.11 & $1.07,1.14$ & & & 1.08 & $1.04,1.12$ \\
\hline In $2010-14$ & & & 1.19 & $1.15,1.24$ & & & 1.16 & $1.12,1.21$ & & & 1.11 & $1.06,1.15$ \\
\hline \multicolumn{13}{|l|}{$50 \cdot 1-100 \cdot 0 \% \mathrm{FPL}$} \\
\hline In 2003-07 & & & 1.05 & $1.02,1.09$ & & & 1.05 & $1.02,1.08$ & & & 1.03 & $1.00,1.07$ \\
\hline In 2010-14 & & & 1.08 & $1.04,1 \cdot 12$ & & & $1 \cdot 12$ & $1.08,1.16$ & & & 1.11 & $1.07,1.15$ \\
\hline \multicolumn{13}{|l|}{$100 \cdot 1-133.0 \% \mathrm{FPL}$} \\
\hline In 2003-07 & & & 1.03 & $1.00,1.07$ & & & 1.03 & $0.99,1.06$ & & & 1.03 & $0.99,1.07$ \\
\hline \multirow{2}{*}{\multicolumn{3}{|c|}{ Wald $x^{2}$ test of interaction $P$ value }} & 1.05 & $1.00,1.09$ & & & 1.06 & $1.01,1.10$ & & & 1.02 & $0.97,1.07$ \\
\hline & & & \multicolumn{2}{|c|}{0.75} & \multicolumn{4}{|c|}{0.017} & & & \multicolumn{2}{|c|}{0.0005} \\
\hline
\end{tabular}

FPL, federal poverty level; Ref., reference group.

Statistically significant $\mathrm{OR}$ at $P<0.05$ are indicated in bold.

†All models adjusted for child's gender and parent race/ethnicity.

income and time period was examined (Table 3, Model 2). The regression coefficient for this interaction term was not statistically significant, suggesting that the effect size of household income on childhood obesity did not change after 2008-09. In other words, disparities in obesity did not change over time (Table 3, Model 2).

Results for 3-year-olds were generally similar to those for 2-year-olds. However, the interaction term (household income $\times$ time period) was statistically significant (Table 3, Model 2). For children living in the lowest-income groups ( $\leq 100 \%$ FPL), the odds of being obese, compared with children from higher-income households, increased by about 5\% from 2003-07 to 2010-14. The greater effect size of household income on obesity after 2008-09 among 3-year-olds translates into widening disparities in obesity. Specifically, between 2003-07 and 2010-14, a greater increase in obesity prevalence occurred among children from the poorest households than among children from the less poor households. Similar results were found among 4-year-old children as those found among 3-yearold children (Table 3).

\section{Household education}

Among 2-year-olds, living in lower-educated households was associated with a statistically significant increase in the odds of obesity compared with children living in college-educated households. Children living in households with less than a high-school education experienced the highest odds of obesity (OR =1.37; $95 \%$ CI 1.31, 1.44; Table 4 , Model 1). Based on the statistically significant interaction term, household education $\times$ time period (Table 4, Model 2), the effect of household education on childhood obesity increased after 2008-09. Children living in households with less than a high-school education experienced the greatest increase in the odds of obesity (from $\mathrm{OR}=1.30$ in 2003-07 to OR $=1.43$ in 2010-14). The increasing effect size of household education on obesity among 2-year-olds translates into widening disparities in obesity after 2008-09.

Similar results were found among 3-year-olds. However, the magnitude of the effect of household education on obesity was not as great as for 2-year-olds. There was no meaningful change in the odds of obesity from 2003-07 to 2010-14 for children with parents with some college education (Table 4, Model 2). Among 4-year-olds, the associations of household education with obesity were similar to those found among the younger children; however, the magnitude of the effect size was smaller among 4-year-olds. The effect size of household education on obesity did not change after 2008-09, suggesting that disparities in obesity by household education did not widen between the two time periods for 4-year-olds. Further study is needed as the individual $t$ statistics of the parameters were statistically significant (data not shown).

\section{Median bousebold income}

Among 2-year-olds, living in lower-income neighbourhoods was associated with a statistically significant increase in the odds of obesity (Table 5, Model 1), with those living in the poorest neighbourhoods $(\leq \$ 32738)$ experiencing the highest odds $(\mathrm{OR}=1 \cdot 15$; $95 \%$ CI $1 \cdot 13$, 1.18). To determine if the effect size of median household income on childhood obesity was significantly different 
Table 4 Multiple logistic regression results: effects of household education on obesity in children of pre-school age participating in the Special Supplemental Nutrition Program for Women, Infants, and Children in Los Angeles County, California, USA, 2003 to $2014 \uparrow$

\begin{tabular}{|c|c|c|c|c|c|c|c|c|c|c|c|c|}
\hline & \multicolumn{4}{|c|}{$\begin{array}{l}\text { 2-year-old children } \\
(n \text { 597506) }\end{array}$} & \multicolumn{4}{|c|}{$\begin{array}{l}\text { 3-year-old children } \\
\text { (n } 577069)\end{array}$} & \multicolumn{4}{|c|}{$\begin{array}{l}\text { 4-year-old children } \\
\text { (n 463213) }\end{array}$} \\
\hline & \multicolumn{2}{|c|}{ Model 1} & \multicolumn{2}{|c|}{ Model 2} & \multicolumn{2}{|c|}{ Model 1} & \multicolumn{2}{|c|}{ Model 2} & \multicolumn{2}{|c|}{ Model 1} & \multicolumn{2}{|c|}{ Model 2} \\
\hline & OR & $95 \% \mathrm{Cl}$ & OR & $95 \% \mathrm{Cl}$ & OR & $95 \% \mathrm{Cl}$ & OR & $95 \% \mathrm{Cl}$ & OR & $95 \% \mathrm{Cl}$ & OR & $95 \% \mathrm{Cl}$ \\
\hline \multicolumn{13}{|l|}{ Education } \\
\hline Less than high school & 1.37 & $1.31,1.44$ & & & 1.25 & $1.20,1.31$ & & & 1.19 & $1.14,1.25$ & & \\
\hline High school & 1.32 & $1.26,1.38$ & & & 1.19 & $1.14,1.24$ & & & 1.13 & $1.08,1.19$ & & \\
\hline $\begin{array}{l}\text { Some college } \\
\text { (College or more, Ref.) }\end{array}$ & 1.21 & $1.15,1.28$ & & & $1 \cdot 15$ & $1.09,1.20$ & & & 1.09 & $1.04,1.15$ & & \\
\hline $\begin{array}{l}2010-14 \text { time period } \\
\text { (2003-07, Ref.) }\end{array}$ & 1.07 & $1.06,1.09$ & & & 1.06 & $1.04,1.07$ & & & 1.03 & $1.01,1.04$ & & \\
\hline \multicolumn{13}{|l|}{ Education $\times$ time period } \\
\hline \multicolumn{13}{|l|}{ Less than high school } \\
\hline In 2003-07 & & & 1.30 & $1.21,1.40$ & & & 1.20 & $1 \cdot 12,1.28$ & & & 1.11 & $1.03,1.19$ \\
\hline In 2010-14 & & & 1.43 & $1.35,1.52$ & & & 1.29 & $1.22,1.37$ & & & 1.25 & $1.18,1.34$ \\
\hline \multicolumn{13}{|l|}{ High school } \\
\hline In 2003-07 & & & 1.26 & $1.17,1.36$ & & & 1.14 & $1.06,1.22$ & & & 1.05 & $0.98,1.14$ \\
\hline In 2010-14 & & & 1.36 & $1.28,1.44$ & & & 1.22 & $1.15,1.29$ & & & $1 \cdot 18$ & $1.11,1.26$ \\
\hline \multicolumn{13}{|l|}{ Some college } \\
\hline In 2003-07 & & & $1 \cdot 18$ & $1.09,1.28$ & & & $1 \cdot 14$ & $1.06,1.23$ & & & 1.02 & $0.94,1.11$ \\
\hline In 2010-14 & & & 1.23 & $1 \cdot 15,1.32$ & & & $1 \cdot 14$ & $1.07,1.21$ & & & 1.14 & $1.06,1.22$ \\
\hline \multicolumn{3}{|c|}{ Wald $x^{2}$ test of interaction $P$ value } & \multicolumn{2}{|c|}{0.043} & \multicolumn{4}{|c|}{0.0066} & & & \multicolumn{2}{|c|}{0.082} \\
\hline
\end{tabular}

Ref., reference group.

Statistically significant $O R$ at $P<0.05$ are indicated in bold.

†All models adjusted for child's gender and parent race/ethnicity.

Table 5 Multiple logistic regression results: effects of median household income on obesity in children of pre-school age participating in the Special Supplemental Nutrition Program for Women, Infants, and Children in Los Angeles County, California, USA, 2003 to $2014 \dagger$

\begin{tabular}{|c|c|c|c|c|c|c|c|c|c|c|c|c|}
\hline & \multicolumn{4}{|c|}{$\begin{array}{l}\text { 2-year-old children } \\
\quad(n 597506)\end{array}$} & \multicolumn{4}{|c|}{$\begin{array}{l}\text { 3-year-old children } \\
\text { ( } n 577069)\end{array}$} & \multicolumn{4}{|c|}{$\begin{array}{l}\text { 4-year-old children } \\
\text { ( } n \text { 463213) }\end{array}$} \\
\hline & \multicolumn{2}{|c|}{ Model 1} & \multicolumn{2}{|c|}{ Model 2} & \multicolumn{2}{|c|}{ Model 1} & \multicolumn{2}{|c|}{ Model 2} & \multicolumn{2}{|c|}{ Model 1} & \multicolumn{2}{|c|}{ Model 2} \\
\hline & OR & $95 \% \mathrm{Cl}$ & OR & $95 \% \mathrm{Cl}$ & OR & $95 \% \mathrm{Cl}$ & OR & $95 \% \mathrm{Cl}$ & OR & $95 \% \mathrm{Cl}$ & OR & $95 \% \mathrm{Cl}$ \\
\hline \multicolumn{13}{|c|}{ Median household incomeł } \\
\hline$\leq \$ 32738$ & 1.15 & $1.13,1.18$ & & & 1.16 & $1.14,1.18$ & & & 1.14 & $1 \cdot 12,1 \cdot 17$ & & \\
\hline$\$ 32739-40278$ & 1.10 & $1.08,1.12$ & & & 1.11 & $1.09,1.13$ & & & 1.11 & $1.09,1.14$ & & \\
\hline $\begin{array}{l}\$ 40279-51534 \\
(\geq \$ 51535, \text { Ref.) }\end{array}$ & 1.05 & $1.02,1.07$ & & & 1.05 & $1.03,1.07$ & & & 1.06 & $1.04,1.09$ & & \\
\hline $\begin{array}{l}2010-14 \text { time period } \\
(2003-07, \text { Ref.) }\end{array}$ & 1.06 & $1.05,1.08$ & & & 1.05 & $1.04,1.06$ & & & 1.02 & $1.01,1.04$ & & \\
\hline \multicolumn{13}{|c|}{$\begin{array}{l}\text { Median household income } \times \text { time period } \\
\leq \$ 32738\end{array}$} \\
\hline In 2003-07 & & & 1.15 & $1 \cdot 12,1 \cdot 18$ & & & $1 \cdot 15$ & $1 \cdot 12,1 \cdot 18$ & & & $1 \cdot 13$ & $1 \cdot 10,1 \cdot 16$ \\
\hline In 2010-14 & & & $1 \cdot 16$ & $1 \cdot 13,1 \cdot 19$ & & & 1.17 & $1 \cdot 14,1 \cdot 20$ & & & 1.15 & $1.12,1.19$ \\
\hline \multicolumn{13}{|l|}{$\$ 32739-40278$} \\
\hline In 2003-07 & & & 1.08 & $1.06,1.11$ & & & 1.11 & $1.08,1.14$ & & & 1.11 & $1.08,1.14$ \\
\hline In 2010-14 & & & 1.11 & $1.08,1.15$ & & & 1.11 & $1.08,1.14$ & & & 1.11 & $1.08,1.15$ \\
\hline \multicolumn{13}{|l|}{$\$ 40279-51534$} \\
\hline In 2003-07 & & & 1.02 & $0.99,1.05$ & & & 1.03 & $1.01,1.06$ & & & 1.06 & $1.03,1.09$ \\
\hline In 2010-14 & & & 1.07 & $1.04,1.10$ & & & 1.08 & $1.05,1 \cdot 11$ & & & 1.07 & $1.04,1 \cdot 10$ \\
\hline \multicolumn{3}{|c|}{ Wald $x^{2}$ test of interaction $P$ value } & & 0.10 & & & & 0.14 & & & & 0.76 \\
\hline
\end{tabular}

Ref., reference group.

Statistically significant $\mathrm{OR}$ at $P<0.05$ are indicated in bold.

†All models adjusted for child's gender and parent race/ethnicity.

flncome measured in 2014 US dollars.

between the two time periods, the interaction term (median household income $\times$ time period) was examined and was found to be statistically insignificant (Table 5, Model 2). The odds of obesity for children living in the lower-income neighbourhoods did not change significantly between
2003-07 and 2010-14, suggesting that the disparities in obesity by median household income did not change between the two time periods (Table 5, Model 2). Similar results were found among the 3- and 4-year-olds (Table 5). 


\section{Discussion}

Among children of pre-school age participating in WIC, we found that household-level socio-economic disparities widened after 2008-09, a time period that included the recession, but neighbourhood-level disparities remained the same. Our findings are consistent with studies among older children which found an increase in household-level socio-economic disparities in obesity over time ${ }^{(30-33)}$. However, two recent studies found that disparities in childhood obesity by household income have not changed $^{(34,35)}$. Despite using multiple disparity indices, Rossen and Schoendorf did not find that income disparities in obesity among children aged 2-18 years changed from 2001 to $2010^{(34)}$. The second study examined the effect of household income on obesity among pre-school-aged children and found that while the overall effect on obesity did not change between 2003-04 and 2011-12, it did weaken among boys ${ }^{(35)}$. The difference in findings between our study and these two could be due to the different study samples. Both previous studies examined a nationally representative sample using National Health and Nutrition Examination Survey data, while our sample was of children living in low-income households. Household income may have a greater effect on obesity risk among low-income families with scarce financial resources. Rossen and Schoendorf also examined disparities among 2-18-year-old children and not solely children of pre-school age. Neither study examined disparities through 2014. Even after the official end of the recession, household income continued to fall ${ }^{(36)}$, income inequality continued to increase and low-SES families' financial situation still had not returned to the levels seen prior to the recession ${ }^{(37)}$, potentially contributing to the widening socio-economic disparities we found. Lastly, the difference in findings could be because our study occurred in California, which was one of the states most affected by the recession $^{(38)}$.

Factors contributing to the widening socio-economic disparities in obesity at the household level are not clear and merit further exploration. Changes in disparities in obesity risk factors might contribute to the widening disparities in obesity. Increasing secular trends in energy intake have been observed among pre-school-aged children in low-education and low-income households since the 1970s, while a decreasing trend has been found among children in college-educated households ${ }^{(39)}$. Although they examined adolescents, Frederick et al. found that while most children decreased energy intake from 1999 to 2010, children in college-educated families experienced the greatest decrease compared with children in families with a high-school degree or less ${ }^{(33)}$. Socio-economic disparities in physical activity also increased, with children in college-educated families becoming more physically active and those in less-educated households becoming less physically active ${ }^{(33)}$.
From Link and Phelan's fundamental cause theory, the widening disparities by household income and education could be because higher-SES individuals are more likely to take advantage of new resources to maintain their health status ${ }^{(40,41)}$. These individuals are more likely to benefit from population-based interventions and efforts since they have greater resources, either income to spend on goods and services, or education to critically think and focus on longterm goals ${ }^{(42)}$. For instance, higher-income families may benefit more from improvements in their food environment since they have more income to spend on food.

Educated parents may experience more control and less chronic psychosocial stress during negative life events like the recession ${ }^{(42)}$, thereby maintaining nurturing, stable environments for their children. Chronically stressed parents and chaotic home environments can increase a child's stress levels, subsequently increasing the child's risk of obesity ${ }^{(43,44)}$. Given that income disparities in obesity increased among the 3- and 4-year-olds and education disparities in obesity increased for the 2- and 3-year-olds, it could be that parents' financial resources became more important after the recession for older children and that education became more important for younger children. While a year or two may not represent a real difference for older children, very young children develop quickly ${ }^{(27)}$. Three- and 4-year-olds need more vigorous activity than 2 -year-olds ${ }^{(45)}$ and income, to the extent that it can provide access to services such as recreational areas, might be more important as children's needs change. Household education might have a greater impact on obesity among younger children to the extent that it is an indicator for household chaos and chronic stress. The effect of chronic stressors on childhood obesity has been found to vary by child's age although greater age differences are generally examined $^{(43)}$. Alternatively, the lack of significant findings for the widening of disparities in obesity by education among 4year-olds may be due to inadequate statistical power.

The lack of change in disparities in obesity by median household income may be partly due to community-based obesity prevention initiatives that have occurred in LAC since 2009. To combat the high prevalence in early childhood obesity in under-resourced communities in LAC, First 5 LA, the LAC Department of Public Health and other organizations invested in Reducing Early Childhood Obesity initiatives such as the Early Childhood Obesity Prevention Initiative ${ }^{(46,47)}$. Many of these initiatives attempted to reduce early childhood obesity risk by improving diet and increasing physical activity and breast-feeding through better access to healthy, fresh foods and recreational facilities for exercise ${ }^{(46,47)}$. These initiatives may have buffered the effects of the recession on neighbourhoods.

The unchanging neighbourhood-level socio-economic disparities could also be due to a major legislative change in 2009 that improved the nutritional quality of foods offered by WIC (72 F.R. 68966). This change increased the availability of healthier foods in neighbourhoods where many WIC-participating families live ${ }^{(48)}$. While some food 
establishments closed during the recession, the food environment might have improved slightly since the density of unhealthy food establishments declined and that of healthy food establishments increased in LAC during the recession ${ }^{(49,50)}$.

To our knowledge, the present study is the first to examine changing socio-economic disparities in obesity among low-income children of pre-school age. Although socio-economic disparities exist among these children ${ }^{(51)}$, studies have until now focused mainly on differences by race/ethnicity and have used only household-level socioeconomic indicators ${ }^{(24,52)}$. Our study uniquely adds to the literature by comparing the effects of neighbourhood-level SES with those of household-level SES, and has several methodological strengths. Studies examining the relationship between economic conditions and weight have used self-reported measurements which are prone to error ${ }^{(8,11)}$. While administrative data were used, the data were of measured heights and weights that have been shown to have high validity ${ }^{(26)}$. The choice of a binary (2003-07 $v$. 2010-14) variable (after examining various approaches to modelling the effects of the recession) provided the flexibility necessary to model the increases in obesity until 2008 separately from the decreases after 2010. The study's large sample size provided a robust sample of very-lowSES households. Finally, although the findings may not be generalizable to other parts of the country, LAC's unique characteristics, such as having one of the largest WIC populations and some of the largest socio-economic inequalities in the $\mathrm{USA}^{(6)}$, made it feasible to examine the effect of SES among a low-income population.

One limitation of the present study is that while we found socio-economic disparities in obesity widened over the time period that included the recession, due to our study design we are not able to conclude that the recession caused this widening. Since it is impossible to have a comparison group (i.e. a group of WIC-participating children who did not experience the recession), we are not able to differentiate the impact of the recession from other factors such as secular changes in obesity, the previously mentioned large-scale obesity prevention initiatives and the 2009 WIC legislative change. We are also missing information on the direct impact of the recession on individual households. Although household income is assessed at each WIC certification or recertification appointment, household education is determined only at child's initial enrolment in WIC and is asked of the parent who accompanies the child to WIC at the time of enrolment. Household education might therefore not accurately represent the highest household educational attainment at the time of the child's measurement.

\section{Conclusion}

To our knowledge, the present study is the first to document socio-economic disparities in obesity among low-income children of pre-school age. Although prevalence of early childhood obesity has been decreasing among low-income children, this decrease masks the experiences of children from the poorest and leasteducated households. During the years following the economic recession, the disparities in obesity by household-level SES widened among low-income children while the disparities by neighbourhood-level SES did not change. While major initiatives were implemented in LAC to address childhood obesity, and these may have buffered the effects of the recession on childhood obesity risk, greater efforts are needed to target the most vulnerable children. Future population health research aiming to address childhood obesity should consider the needs of the most vulnerable children: those from the poorest and least-educated households.

\section{Acknowledgements}

Acknowledgements: The authors thank Lizbeth Delatorre for assistance with formatting the manuscript, and gratefully acknowledge Dr Evelyn Blumenberg, Dr Judith Siegel, Kiran Saluja, Judy Gomez, Mike Whaley and Armando Jimenez for their contributions to this work. Financial support: This work was supported by the Eunice Kennedy Shriver National Institute of Child Health and Human Development (NICHD) (T.Z.N., C.C.M., M.L.P., M.C.W., grant number 1R01HD072296); and by First 5 LA (T.Z.N., S.E.W.), a child advocacy and grant-making organization created by California voters to invest Proposition 10 tobacco taxes to improve the lives of children from prenatal to age 5 in Los Angeles County. The study also benefited from resources provided by the UCLA California Center for Population Research, which receives core support from NICHD (P2C-HD041022). NICHD and First 5 LA had no role in the design, analysis or writing of this article. Conflict of interest: None. Authorship: T.Z.N. formulated the research question, carried out the analyses and drafted the initial manuscript. S.E.W., C.M.C., M.L.P. and M.C.W. helped conceptualize the study and reviewed and revised the manuscript. Ethics of human subject participation: The study protocol was approved by the UCLA Institutional Review Board.

\section{Supplementary material}

To view supplementary material for this article, please visit https://doi.org/10.1017/S1368980018000666

\section{References}

1. Morin R (2010) One Recession, Two Americas. Washington, DC: Pew Research Center; available at http://www.pewso cialtrends.org/2010/09/24/one-recession-two-americas/ 
2. Tekin E, McClellan C \& Minyard KJ (2013) Health and Health Behaviors During the Worst of Times. Cambridge, MA: National Bureau of Economic Research; available at http://www.nber.org/papers/w19234.pdf

3. Hoynes H, Miller DL \& Schaller J (2012) Who suffers during recessions? J Econ Perspect 26, 27-48.

4. Pfeffer FT, Danziger S \& Schoeni RF (2013) Wealth disparities before and after the great recession. Ann Am Acad Pol Soc Sci 650, 98-123.

5. Bacigalupe A \& Escolar-Pujolar A (2014) The impact of economic crises on social inequalities in health: what do we know so far? Int J Equity Health 13, 52.

6. PolicyLink \& PERE (2017) An Equity Profile of The Los Angeles Region. Oakland, CA: PolicyLink and PERE; available at http://www.dornsife.usc.edu/assets/sites/242/docs/ EquityProfile_LA_Region_2017_Full_Final_Web.pdf

7. Ruhm CJ (2003) Good times make you sick. J Health Econ 22, 637-658

8. Ruhm CJ (2000) Are recessions good for your health? QJ Econ 115, 617-650.

9. Ruhm CJ (2005) Healthy living in hard times. J Health Econ 24, 341-363.

10. Xu X (2013) The business cycle and health behaviors. Soc Sci Med 77, 126-136.

11. Charles KK \& DeCicca P (2008) Local labor market fluctuations and health: is there a connection and for whom? $J$ Health Econ 27, 1532-1550.

12. Arcaya M, Glymour MM, Chakrabarti P et al. (2013) Effects of proximate foreclosed properties on individuals' weight gain in Massachusetts, 1987-2008. Am J Public Health 103, e50-e56.

13. Currie J, Duque V \& Garfinkel I (2015) The Great Recession and mother's health. Econ J (Lond) 125, F311-F346.

14. Oddo VM, Nicholas LH, Bleich SN et al. (2016) The impact of changing economic conditions on overweight risk among children in California from 2008 to 2012. J Epidemiol Community Health 70, 874-880.

15. Burgard SA \& Kalousova L (2015) Effects of the Great Recession: health and well-being. Annu Rev Sociol 41, 181-201.

16. Colman G \& Dave D (2013) Exercise, physical activity, and exertion over the business cycle. Soc Sci Med 93, 11-20.

17. Todd JE (2017) Changes in consumption of food away from home and intakes of energy and other nutrients among US working-age adults, 2005-2014. Public Health Nutr 20, 3238-3246.

18. Dave DM \& Kelly IR (2012) How does the business cycle affect eating habits? Soc Sci Med 74, 254-262.

19. Ruhm CJ (2015) Recessions, healthy no more? J Health Econ 42, $17-28$

20. Miller A, Dawson L \& Welker E (2017) Stress in Early Life and Childhood Obesity Risk. Durham, NC: Healthy Eating Research; available at http://www.healthyeatingresearch.org/ wp-content/uploads/2017/06/her_stress_obesity_5-30.pdf

21. Thorn B, Tadler C, Huret N et al. (2015) WIC Participant and Program Characteristics 2014. Prepared by Insight Policy Research under Contract No. AG-3198-C-11-0010. Alexandria, VA: US Department of Agriculture, Food and Nutrition Service.

22. PHFE-WIC \& First 5 LA (2017) Los Angeles County WIC Data. http://www.lawicdata.org/ (accessed September 2017).

23. Pan L, Freedman DS, Sharma AJ et al. (2016) Trends in obesity among participants aged 2-4 years in the Special Supplemental Nutrition Program for Women, Infants, and Children - United States, 2000-2014. MMWR Morb Mortal Wkly Rep 65, 1256-1260.

24. Sekhobo J, Edmunds L, Whaley S et al. (2013) Obesity prevalence among low-income, preschool-aged children New York City and Los Angeles County, 2003-2011. MMWR Morb Mortal Wkly Rep 62, 17-22.
25. Chaparro MP, Wang MC \& Whaley SE (2013) Neighborhood Obesity Trends Among 2-5 Year Old Children Participating in the Special Supplemental Nutrition Program for Women, Infants and Children (WIC) in Los Angeles County, 20022011. Los Angeles, CA: First 5 LA; available at http://www. first5la.org/files/08149_FinalReport_06302013.pdf

26. Crespi CM, Alfonso VH, Whaley SE et al. (2012) Validity of child anthropometric measurements in the Special Supplemental Nutrition Program for Women, Infants, and Children. Pediatr Res 71, 286-292.

27. Tanner JM (1990) Foetus Into Man: Physical Growth from Conception to Maturity, revised and enlarged ed. Cambridge, MA: Harvard University Press.

28. Kuczmarski RJ, Ogden CL, Guo SS et al. (2002) 2000 CDC growth charts for the United States: methods and development. Vital Health Stat 11, issue 246, 1-190.

29. US Census Bureau (2016) 2014 American Community Survey 1-Year Estimates. Table B19013. Median household income in the past 12 months. https://factfinder.census.gov/ faces/tableservices/isf/pages/productview.xhtml?pid=ACS_14 1YR_B19013\&prodType=table (accessed September 2017).

30. Singh GK, Siahpush M \& Kogan MD (2010) Rising social inequalities in US childhood obesity, 2003-2007. Ann Epidemiol 20, 40-52.

31. May AL, Freedman D, Sherry B et al. (2013) Obesity United States, 1999-2010. MMWR Suppl 62, 120-128.

32. Babey SH, Hastert TA, Wolstein J et al. (2010) Income disparities in obesity trends among California adolescents. Am J Public Health 100, 2149-2155.

33. Frederick CB, Snellman K \& Putnam RD (2014) Increasing socioeconomic disparities in adolescent obesity. Proc Natl Acad Sci U S A 111, 1338-1342.

34. Rossen LM \& Schoendorf KC (2012) Measuring health disparities: trends in racial-ethnic and socioeconomic disparities in obesity among 2- to 18-year old youth in the United States, 2001-2010. Ann Epidemiol 22, 698-704.

35. Kranjac AW \& Wagmiller RL (2016) Association between age and obesity over time. Pediatrics 137, e20152096.

36. Kochhar R (2012) A Recovery No Better Than the Recession. Washington, DC: Pew Research Center; available at http:// www.pewsocialtrends.org/2012/09/12/a-recovery-no-betterthan-the-recession/

37. Bohn S \& Danielson C (2016) Income Inequality and the Safety Net in California. San Francisco, CA: Public Policy Institute of California; available at http://www.ppic.org/ content/pubs/report/R_516SBR.pdf

38. Bohn S \& Schiff E (2011) The Great Recession and Distribution of Income in California. San Francisco, CA: Public Policy Institute of California; available at http://www.ppic. org/content/pubs/report/R_1211SBR.pdf

39. Kant AK \& Graubard BI (2013) Family income and education were related with 30-year time trends in dietary and meal behaviors of American children and adolescents. J Nutr 143, 690-700.

40. Burgard SA \& Hawkins JM (2014) Race/ethnicity, educational attainment, and foregone health care in the United States in the 2007-2009 recession. Am J Public Health 104, e134-e140.

41. Link BG \& Phelan J (1995) Social conditions as fundamental causes of disease. J Health Soc Behav Spec No, 80-94.

42. Cutler DM \& Lleras-Muney A (2008) Education and health: evaluating theories and evidence. In Making Americans Healthier: Social and Economic Policy as Health Policy, pp 29-60 [J House, R Schoeni, G Kaplan et al., editors]. New York: Russell Sage Foundation.

43. Garasky S, Stewart SD, Gundersen C et al. (2009) Family stressors and child obesity. Soc Sci Res 38, 755-766.

44. Gundersen C, Mahatmya D, Garasky S et al. (2011) Linking psychosocial stressors and childhood obesity. Obes Rev 12, e54-e63. 
45. Tremblay MS, Chaput J-P, Adamo KB et al. (2017) Canadian 24-hour movement guidelines for the early years ( $0-4$ years): an integration of physical activity, sedentary behaviour, and sleep. BMC Public Health 17, 874 .

46. ChooseHealthLA! (2013) Early Childhood Obesity Prevention Initiative. Los Angeles, CA: LA County Department of Public Health; available at http://www.publichealth. lacounty.gov/chronic/docs/20131227_Early_Childhood.pdf

47. First 5 LA (2014) Appendix A: First 5 LA projects related to childhood obesity prevention. http://www.first5la.org/files/ First5Programs.pdf (accessed January 2018).

48. Schultz DJ, Byker Shanks C \& Houghtaling B (2015) The impact of the 2009 Special Supplemental Nutrition Program for Women, Infants, and Children food package revisions on participants: a systematic review. J Acad Nutr Diet 115, 1832-1846.
49. Nobari TZ, Blumenberg E, Chaparro PM et al. (2014) The food environment of immigrant enclaves in Los Angeles County. Presented at 2014 Annual Meeting of the Population Association of America, Boston, MA, USA, 1-3 May 2014. http://www.paa2014.princeton.edu/papers/142394 (accessed January 2018).

50. Hsu T (2012) Independent restaurants hardest hit by slow restaurant traffic. The Los Angeles Times, 27 February 2012. http://www.articles.latimes.com/2012/feb/27/business/ la-fi-mo-independent-restaurant-visits-20120227 (accessed January 2018).

51. Freedman DS, Sharma AJ, Hamner HC et al. (2017) Trends in weight-for-length among infants in WIC from 2000 to 2014. Pediatrics 139, e20162034.

52. Pan L, McGuire LC, Blanck HM et al. (2015) Racial/ethnic differences in obesity trends among young low-income children. Am J Prev Med 48, 570-574. 